\title{
Study on Influences of Chinese Folk Art Forms on Ceramic Art
}

\author{
Changzong Shao \\ School of Ceramic Art \\ Jingdezhen Ceramic Institute \\ Jingdezhen, China 333403
}

\begin{abstract}
Folk art, originated from the economic pattern of self sufficiency, may get involved in all aspects of the people such as emotion, thought, living habits and so on. It is closed to the daily life of the people, and the fork art rooted in the daily life of the people has thick living root and land features. Its simple and sincere connotation of beauty and its perfect combination of spirits and substances have achieved the high unification. The design and color of ancient folk art and some lucky implication have become the resources inexhaustible for ceramic art.
\end{abstract}

\section{Keywords-folk art; thought; ceramic art}

\section{INTRODUCTION}

Folk art is artistic form which was formed unceasingly through collective heritage and cultural deposition by common laborers according to the needs of themselves during the development. It has many forms such as folk sculpture, shadow puppet, folk paper cutting and drawing, which carry the ideal and wish of the people. Folk art has basic nature of original culture, inheriting and developing natural culture of China and symbolizing deep level meaning of Chinese culture. The folk art in China, which contains all kinds of colors and designs, are fortunes inexhaustible for the ceramic design.

\section{COLORS OF FOLK ART}

\section{A. Characteristics of Colors}

Color is a tool to express feelings, which may increase the infection and shock of ceramic art products largely. The color design may influence psychological changes of the people such as connection, perception, feeling and so on, bringing a visual shock to the people, the role of colors has been widely accepted by the people. Color contains rich creative elements, it is connected with the feeling and psychology of the people to some degree, for example, red stands for active and passionate; green makes us feel cool and moist; white shows us clean and pure; blue makes us feel calm and fresh; pink make us feel warm and lovely; yet black us feel serious and so on. Actually the information that colors in folk art delivers more than the above, through visual effect; it can bring us different feelings such as happy, distressed, sad, joyful and so on. Besides, feelings that colors bring us vary with ethnic group, region and culture. The difference in culture may lead to a difference in perception, habit and concept. Accordingly the same color seen by different people will bring different feelings. In a word, in addition to the original colors of things, colors contain meanings of aesthetic form and spiritual demand of the whole ethnic group. Colors have been widely used in folk art such as paper cutting, new year pictures, which show colorful contents, such as folk art symbols showing the wisdom of the people. The connotation has been fart exceeding the aesthetic function offered by colors, which provide diverse and abundant basic resources for the folk art especially for the development of ceramic art industry.

\section{B. Folk Colors Shown in Ceramic Art Works}

The folk art in China belongs to conceptual art, so do colors. Traditional philosophy thought in China makes the colors in folk art show strong aesthetic and affective characteristics, which largely are influenced by traditional Chinese folk customs and habits. Concepts are simply thought as thing lucky and propitious by the people in order to counteract evil forces, finally it develops into festival features in folk art. Many words such as a riot of color stands for joyous and lucky, there are more words showing colors, which generally stands for good luck, and many words describing colors have become conceptual modeling languages, deeply impressed in heats of the people. Besides, it has been widely used in the design of ceramic art products, based on the ceramic design, concepts and beliefs of the nation are added therein to show national characteristics and culture. It has greatly exceeded the function to simply deliver colors, and to some degree, it works to "express what they think through colors".

\section{Application OF NATiOnal ART IN THE Design OF CERAMIC ART PRODUCTS}

Chinese folk art is diverse in form, and it has greatly influenced and promoted the development of ceramic art, such as paper cutting, lacquerware process, weaving, embroidery, colored drawing and so on, which all are treasure formed in the brilliant culture in China after more than five thousands years, we must carry them forward and push it to develop.

There are a great number of designs in folk art, and each pattern and drawing are not stored simply, reasons for their 
hand-down up to now are not limited to beautiful colorful design, what is important is the thick cultural atmosphere hidden inside, During the thousand of development of Chinese nation, folk art has been inherited and developed, which recorded the rough course of Chinese culture as well as the achievements of communicating with foreign countries. Just like a historical play worth tasting carefully; and its connotation of information and culture still need to be further dug by scientists. During the creation of ceramic art products, generally designers put artistic designs such as paper cutting, new-year picture and so on inside for application so as to improve the cultural connotation and artistic tastes, relying on traditional process techniques such as sculpture, carving, trimming and glazing colors so that the ceramic art takes on a richer sense of art. The activity where national fine art language is connected with the value practice is a kind of art of decoration, an inheritance, creation and application of national artistic designs, which fully shows the nation's spirits to inherit and carry forward the culture of its own.

Paper cutting art gets involved in all kinds of fields, there are all kinds of technique of expression such as Yang paper cutting, Yin paper cutting, paper cut silhouette and so on, there is a long history and wonderful stories. The paper cutting technique has all kinds of themes, of which some have shown and described more than living phenomena, they have special meanings and rich connotation in culture.

The earliest time to apply paper cutting art in ceramic art was in late Tang Dynasty. The ceramic products burned with twice glazing colors take on decorative patterns with layers, showing an effect of paper cutting, it looks goods with senses of layers. Modern artists connect paper cutting with ceramics through new techniques, then added with modern fashionable elements, and the new artistic expression forms made skillfully integrate modern characteristics and traditional culture, opening a new thought way for the development of folk art.

Folk art is a language of life and more of art, to which, the people place their feelings and materialize the feelings in life. It has become a bridge and link of laborers and creators, showing what the people can create through all kinds of art forms. Folk art is a creation closely related to the production and life of the people, which may enrich and fill our social life. And the creation and thinking pattern, language styles and feeling expression of folk art have features of their own. Generally ceramic art and folk art share the roots, pottery shreds dug from primitive communes showed diverse designs and symbols marking some functions. For folk art get involved in all kinds of fields, it can provide rich nutrients and experience for the design of ceramic art products.

\section{MEANING OF LUCKY DESIGNS}

Gook luck is a kind of nice sign, symbolizing happiness, kindness, joyfulness. Good luck designs may adopt flowers, birds, beasts, figures or lucky characters. Such characters can be luck expressions, sayings or fairy stores, and rhetorical devices such as analogy, pun or metaphor can be used so as to express the beauty of folk art through one phase for one figure. In addition to these used to show the happiness of the people, it can be also used to leave deep longing, expectation for long life and ideas of all kinds of luck and celebration. It can be said that good luck is a constant theme that has lasted for thousands of years in the country, in the meantime, it is shown in the design of ceramic art, and many artists show the rich cultural connections of modern ceramic art and modern characteristics of energy through homophone, analogy and implication and so on.

Symbol brings a meaning similar according to the specific form, color and habits of things. For example, mandarin duck symbolizes couples, peony symbols wealth and rank, bamboo symbolizes gentleman, lotus symbolizes noble and pure and so on. Homophony is originally used in literatures, which is used in folk art to show good lock, for example, before a marriage, Chinese dates symbolize "to birth a baby early", fish is generally provided at tables, which symbolizes "abundant foods left at the year end", rice cake has the same pronunciation as "promotion", symbolizing promotion gradually.

\section{CONCLUSION}

Chinese folk art has abundant contents, wide themes and diverse forms, which are invaluable assets left to us by ancestors, after thousands of years of development and inheritance, it has be integrated to every aspects of our life. Therefore, ceramic artists have done well to integrate folk art to ceramic art through continuous exploration in the folk art, besides; modern elements are placed in it, fully showing the inheritance and development of traditional national culture.

\section{REFERENCES}

[1] Wan Yuanyuan, Influences of Traditional Chinese Paper Cutting on Ceramic Art, Exhibition of Chinese Art, Issue No.1, 2012.

[2] Wu Weina, Discussion on Leading Thought for Design of Ceramic Art, Archives, Issue No.10, 2013.

[3] Gao Na, Influence of Folk Art Elements on Modern Ceramic Art, Design Art, Qingdao University, 2010 (Year to Grant Degree). 